\title{
Region, Social Identities, and Disclosure Practices as Predictors of Heterosexist Discrimination Against Sexual Minorities in the United States*
}

\author{
Eric Swank, Morehead State University \\ Breanne Fahs, Arizona State University \\ David M. Frost, Columbia University
}

\begin{abstract}
Exposure to heterosexist discrimination may vary by a person's place of residency. Utilizing a minority stress perspective, an online survey of self-identified lesbian, gay, and bisexual (LGB) individuals $(n=285)$ examined whether rural and small town inhabitants experienced greater exposure to six types of enacted stigma. After comparing the frequency of enacted stigma by community type, findings demonstrated that rural LGBs reported experiencing more homophobic statements, property damage, and employment discrimination than urban LGBs. Small town LGBs also encountered additional amounts of housing discrimination and were more often chased by strangers compared with urban sexual minorities. Finally, disclosure practices and hierarchies based on race and social class also influenced exposure to discrimination. The importance of spatial factors often intensified when respondents disclosed their sexual identity more publicly. When exploring racial and class differences, affluent sexual minorities experienced less employment discrimination and white sexual minorities were less likely to experience several forms of heterosexist events (especially being punched and kicked).
\end{abstract}

Discrimination against lesbian, gay, and bisexual (LGB) individuals is common and multidimensional. In its most explicit forms, heterosexist behavior manifests itself through physical violence and language that chastises and demeans homosexuality and non-normative gender behavior. In slightly subtler forms, heterosexism and heteronormativity inform many insidious practices that privilege heterosexuality while denigrating sexual minorities. Through these practices, LGBs often endure hostile environments that monitor and penalize homosexual behavior in the United States.

LGB individuals' experiences of stigma, prejudice, and discrimination, which result from heteronormativity and heterosexism, ${ }^{1}$ have been usefully conceptualized as constituting minority stress (Meyer 2003). Minority stress theory is based in social stress theory, which posits that stressors constitute any factors or conditions that require individuals to adapt to changes intrapersonally, interpersonally, or in their environments. Meyer (2003) posited that minority stressors can be usefully conceptualized along a continuum of proximity to the 
self. Stressors most distal to the self are objective stressors based primarily in the environment, such as prevailing stereotypes, prejudice, and discrimination. Most proximal to the self are people's internalizations of negative social attitudes toward their own minority group (e.g., internalized contempt for one's sexual identity). Institutionalized heterosexism and hate crimes directed toward LGB individuals are located on the most distal end of this continuum, because they stem directly from the social environments in which LGBs experience their lives.

Studies on the prevalence of heterosexist discrimination are somewhat common, while research on how victimization rates may vary for different subgroups is rarer. ${ }^{2}$ There are some "double oppression" studies that explore the ways that heterosexist discrimination may be modified along race, class, and gender lines (D'Augelli and Grossman 2001; Meyer, Schwartz, and Frost 2008; Szymanski and Sung 2010). Unfortunately, less attention has been paid to the macro and structural factors that predict shifting patterns in heterosexist discrimination. Some initial studies suggest that electoral votes on same-sex marriage (Rostosky et al. 2009) or increases in poverty and unemployment can trigger increased rates of hate crimes against gays and lesbians (Alden and Parker 2005; Green, Glaser, and Rich 1998). Even fewer studies have explored the relationship between spatial factors and discriminatory practices (Barton 2012; Gonzalez et al. 2009; Kosciw, Greytak, and Diaz 2009; Waldo, Hesson-McInnnis, and D'Augelli 1998). To build upon this nascent literature, this article explores the links between sexual minorities' place of residency and their exposure to heterosexist discrimination. Moreover, this study addresses whether urban and rural differences remain important after one controls for race, class, gender, and sexual identity disclosure.

\section{Location and Gender Expectations}

Urban sociologists like Wirth (1938) and Fischer (1975) argue that nations, regions, and localities can distinguish their cultures from one another through the historical interplay of many social processes (e.g., amount of industrialization, degree of racial-class-age heterogeneity, migration practices, population density, type of social networks available). Rural areas, or spaces that have high land-to-human ratios and an economic dependence on farming, mining, and forestry, have often been conceptualized as communities that prize cultural homogeneity, localism, religiosity, and "traditional values" (Miller and Luloff 1981). In contrast, Wirth (1938) argued that the "urban way of life" generally disrupts ethnocentric and authoritarian perspectives. Due to macro issues of city size, population density, and greater cultural heterogeneity, city dwellers regularly encounter social systems that transmit new, unique, and incompatible moral messages. To cope with diverse and sometimes contradictory social cues, 
city dwellers must learn how to respond to a wider range of opinions as they try to reconcile competing moral and behavioral expectations. This adaptation then normalizes flexibility in thought and a greater tendency to accept practices that could be considered unconventional or strange in more rural and small town settings.

Adding to these contextual factors are possible compositional effects; that is, cities or regions may hold higher concentrations of people who possess the traits associated with liberalism - such as higher education levels, less religious fundamentalism, or general inclination to not see diversity as a threat (Moore and Vanneman 2003; Van Dyke, Soule, and Windom 2001). In fact, Johnson and Stokes (1984) contended that the greater conservatism of southern communities is partly due to greater prevalence of personal piety (e.g., prayer) and the acceptance of orthodox-fundamentalist religious beliefs (e.g., the Bible is inerrant, the ubiquity of human sinfulness, or the fear of eternal damnation at the hands of a punitive God).

Studies that link heterosexism to regional variation have mostly followed two approaches. When addressing attitudes toward traditional gender roles and negativity toward heterosexuals, some studies have explored the possibility of gender and sexuality attitudes being spatialized (Baunach, Burgess, and Muse 2010; Carter and Borch 2005; Eldridge, Mack, and Swank 2006; Moore and Vanneman 2003). Several space-based studies note that traditional gender and sexuality scripts are expressed more frequently by people who resided in small town or rural communities (Andersen and Fetner 2008; Bolzendahl and Myers 2004; Loftus 2001; Rice and Coates 1995; Rosenfeld and Kim 2006), and southern or more rural states are more likely to have laws that ban same-sex marriages (Kane 2007; McVeigh and Maria-Elena 2009; Soule 2004).

\section{Location and Discrimination Against Sexual Minorities}

The empirical literature on how discrimination and minority stress vary across community contexts is less prolific. Since the mid-1990s, there has been a small upsurge in the number of qualitative studies of rural sexualities (e.g., Barton 2010; Gray 2009; Kazyak 2011; McCarthy 2000). Rural-living LGBs overwhelmingly described living in bleak and inhospitable social climates. Findings from these studies highlight hostile rural communities that forced sexual minorities into silence, social isolation, and fear of hate crimes. In total, the narratives in qualitative studies depict rural landscapes as oppressive places to flee from, while cities are viewed as a better, safer, and more enjoyable context (unfortunately, none of these studies compared these narratives to those of urban LGBs).

Quantitative studies that analyze minority stress variation by region are less consistent in their results than qualitative studies (Gonzalez et al. 2009; 
Johnson et al. 2005; Kosciw, Greytak, and Diaz 2009; Connolly and Leedy 2007; Waldo, Hesson-McInnnis, and D'Augelli 1998). One study noted that rental discrimination for same-sex parents is worse within certain residential neighborhoods of Canadian cities (Lauster and Easterbrook 2011), while another study discovered spatial variance in the hiring practices of sexual minorities (Tilcsik 2011). With regard to homophobic bullying, a recent study of Canadian LGB adolescents noted that rural youths were confronted more with verbal teasing and physical assaults than their metropolitan counterparts (Poon and Saewyc 2009). Also, LGB high school students who attended urban schools heard less homophobic remarks and dealt with less sexual harassment related to sexual identity compared with their heterosexual counterparts (Kosciw, Greytak, and Diaz 2009). Other survey-based studies partially confirmed aspects of the rural toxicity argument. A recent sample from Wyoming noted that lesbians, but not gay men, in smaller towns faced greater levels of public discrimination than lesbians in larger cities (Connolly and Leedy 2007). Similarly, rural lesbian mothers experienced more public harassment and rejection than urban lesbian moms, but the spatial differences disappeared when addressing homophobic comments by relatives (Puckett et al. 2011). Finally, heterosexist verbal abuse, but not violent hate crimes, was more common among rural gay men in Kentucky (Tewksbury et al. 1999).

In contrast, other studies have detected no urban or rural effects on the experience of minority stress for LGBs (Gonzalez et al. 2009). Weston's (1995) ethnography suggests that narratives of urban-rural differences are mostly a dream and "sexual imaginaries" of this sort generally lead to great disappointments for rural LGBs who move to the cities. In quantitative literature, a study of LGB senior citizens in nursing homes found that community size did not predict the amount of discrimination they noted from administrators, staff, and other residents (Johnson et al. 2005), and a study of LGB college students found urban and rural respondents reported similar levels of verbal or physical harassment (Waldo, Hesson-McInnnis, and D'Augelli 1998). Lastly, another study found that place of residency was unrelated to levels of internalized homophobia, stigma consciousness, and the amount of "outness" among urban and rural lesbian mothers (Puckett et al. 2011).

\section{Social identities and Exposure to Heterosexism}

Sexual minorities who reside in the same area do not always share the same social locations in race, class, and gender hierarchies. For example, due to a "matrix of oppressions," intersectional theorists argue that affluent white lesbians generally have different life experiences, obligations, and expectations than poor black lesbians and gay men (Collins 1990). While exploring double or interlocking oppressions, some studies suggest that sexual minority African Americans, 
Latina/os, and Asian Americans probably face greater stigma and hostility about their sexual orientation than whites (Chae and Ayala 2010; Diaz et al. 2001; Szymanski and Sung 2010). For example, surveys have often found elevated levels of homonegativity among African Americans, Asian Americans, and Latina/os (Lewis 2003; Loftus 2001; Schulte and Battle 2004), while black lesbians faced more resentment when they "came out" to family members and friends (Grov et al. 2006; Mezey 2008). Other studies suggest that African American and Latino/a sexual minorities report high levels of racism in the dating scene (Balsam et al. 2011). Additionally, LGBT African Americans and Latina/os may suffer more from lower salaries and fewer career advancements compared with white sexual minorities (Elmslie and Tebaldi 2007; Lombardi et al. 2001; Ragins and Cornwell 2001). Finally, racial backgrounds and exposure to heterosexist discrimination might also be related. Some studies suggest that white sexual minorities were less likely to experience event-based forms of discrimination and victimization, such as physical or sexual assaults, because of their sexual identity (Berrill 1990; Meyer, Schwartz, and Frost 2008), while others suggested that racial differences in hate crimes were much stronger for lesbians (Dunbar 2006). Other studies suggest that homophobic hate crimes and everyday discrimination did not vary by race (Herek 2009; Huebner, Rebchook, and Kegeles 2004; Pilkington and D’Augelli 1995).

The gender of sexual minorities can alter the types of discrimination experienced. Numerous studies have found that gay men generally experienced more homophobic threats and fist fights than lesbians (Berrill 1990; D'Augelli and Grossman 2001; Herek 2009; Tewksbury et al. 1999), but stranger-induced sexual assaults happened more to lesbians than gay men (Balsam, Rothblum, and Beauchaine 2005; D'Augelli and Grossman 2001). When dealing with dayto-day interactions, gay men often reported being treated with more respect and courtesy by family members and schoolmates, but gay men often encountered more hostile neighbors than lesbians (Meyer, Schwartz, and Frost 2008; Pilkington and D'Augelli 1995; Puckett et al. 2011).

The discussion on different economic opportunities for gay men and lesbians has yielded even more complications. One study found that lesbian mothers encountered more rental discrimination than gay fathers (Lauster and Easterbrook 2011). When at work, lesbians often reported greater workplace discrimination than gay men (Ragins and Cornwell 2001), but differences in salary between gay men and lesbians were not substantial (Blanford 2003; Elmslie and Tebaldi 2007). These mixed findings suggest that gay men may avoid more blatant forms of workplace discrimination than lesbians, but male privilege in salaries is less consequential for gay than heterosexual men.

Membership in certain social classes can influence exposure to heterosexist discrimination (Chae and Ayala 2010). Poor and working-class heterosexuals 
were less supportive of same-sex marriages (McVeigh and Maria-Elena 2009) and displayed more hostility toward sexual minorities (Andersen and Fetner 2008). Accordingly, more affluent gays and lesbians may have the money to buy into safer communities, while poorer sexual minorities often cannot afford to live in these more hospitable enclaves (Barrett and Pollack 2005). Because of corporate power structures, it is likely that business owning, managerial, and professional LGBs experience less employment discrimination than sexual minorities with working-class jobs (Diaz et al. 2001; Lombardi et al. 2001).

\section{Discrimination and Disclosure Patterns}

Public acknowledgements of sexual identities are often crafted through a complicated set of disclosure practices (Ward and Winstanley 2006). Some sexual minorities may feel comfortable revealing their sexual identity in most settings, while others may only hint at their sexual identity to a few confidants or nobody at all. Disclosures of sexuality are often strategic, as revealing one's "real" sexual identity can carry benefits and risks depending on the reactions of audience members. While being "out" means that people could have greater access to supportive communities, being labeled as a sexual minority also increases the chances of encountering heterosexist rejection and discrimination (Lombardi et al. 2001; Szymanski and Sung 2010). In fact, some studies concluded that LGBs who have been out longer, or tell more people of their sexual identity, were more likely to experience verbal harassment and physical hate crimes than LGBs who reported less disclosure (D’Augelli and Grossman 2001; Huebner, Rebchook, and Kegeles 2004; Taylor and Raeburn 1995; Tewksbury et al. 1999).

\section{The Current Study}

This study addresses possible location-based differences in exposure to forms of enacted stigma by addressing the following research questions: (1) Does living in rural or urban communities influence the amount of discriminatory experiences that sexual minorities endure? (2) Does disclosure of sexual minority identity result in increased exposure to cases of enacted stigma? (3) Does the association between location (urban versus rural) and enacted stigma depend on sexual identity disclosure? And finally, (4) Do spatial factors influence the exposure to hate crimes and other forms of enacted stigma even after controlling for race, class, and gender?

\section{Method}

\section{Participants}

This online study drew from a sample of 285 LGB-identified women and men recruited from throughout the United States in December 2007. Participants 
were recruited through ten e-mail listservs that served self-identified lesbians, gays, and bisexuals. Because the sample was part of a larger study on the political participation of gay men and lesbians, two of the listservs contained members of "Fairness Alliances" that sought equality for LGBs. Memberships in these e-mail groups were free, and most of their participants resided in Midwestern and Mid-Atlantic states. The other eight listservs provided less explicitly politically engaged networks. When finding these e-mail groups, we selected Yahoo groups that met three criteria. First, the group had to exist for explicitly social purposes (i.e., they did not mention anything political in the description of their listserv). Second, we excluded groups that seemed to serve as romantic or sexual match-making sites to avoid biasing the sample with an overrepresentation of single participants. Finally, to lessen problems of selection bias along spatial lines, we looked for groups that mentioned the regions that were most common in the political listservs (e.g., Queer Kentucky).

The cover letters sent via the listservs asked potential respondents to click on a link that took them to the study's Web site. The letter solicited the involvement of adults who self-identified as LGB. As expected, the letter stated that involvement in this project was anonymous and voluntary.

The sample of 285 participants had a preponderance of males (58\% male) and a mainly white racial composition (79\% European American, 7\% Native American, 2\% African American, 1\% Asian American, 1\% Latina/o, and 10\% "refuse to answer"). Ages in the sample spanned a wide range, from age 18-75, with 24 percent under age 30, 54 percent ages 30-50, and 22 percent ages 51$75($ mean $=39.75, \sigma=12.19)$. The sample included a diverse array of incomes, including 10 percent below $\$ 20,000$ per year, 27 percent below $\$ 20,000-50,000$ per year, 25 percent below 50,000-80,000 per year, and 31 percent over $\$ 80,000$ per year, with 8 percent missing data. Our sample was highly educated, with 3 percent having earned a high school degree, 58 percent having some college or a bachelor's degree, and 32 percent having a graduate degree. Participants tended to be distributed in many types of urban and rural spaces, with 26 percent residing in a center city of large urban center, 18 percent residing in a suburb of a large urban center, 18 percent residing in a midsized city, 23 percent residing in small towns, and 9 percent living in rural areas. Because the political listservs were connected to a Kentucky organizations, 65.2 percent of participants lived in the South, 15.7 percent lived in the Midwest, 6.2 percent lived in the West, and 4 percent lived in the East (with Kentucky, Ohio, Indiana, Tennessee, and West Virginia representing the most respondents).

\section{Measures}

Discriminatory Experiences. Gregory Herek (2009) specified methods to estimate the prevalence of discrimination against LGBs (see also D'Augelli and 
Grossman 2001). Herek operationalized the concept of "enacted" stigma by measuring manifestations of discrimination directed against people who are presumed sexual minorities. Enacted stigma is defined as the situations in which people, groups, or institutions explicitly dismiss, denigrate, or attack a person because they are not seen as a heterosexual.

This study separately analyzed six forms of enacted stigma that had occurred in the past year, as each form of enacted stigma was measured through a single item. Three dependent variables concentrated on personal experiences of interpersonal hate acts. When focusing on being targeted because of their sexual identity, one item asked participants whether they have been "punched, hit, kicked, or beaten," while other items asked whether they were "chased or followed" or "had personal property destroyed or damaged." One dependent variable dealt with the frequency of encountering homophobic condemnations. Instances of verbal degradation were assessed through an item on how often participants "confront people who make homophobic statements." Two variables traced issues of economic discrimination. To measure employment and housing biases, respondents were asked whether they were "denied or fired from a job" or "prevented from moving into an apartment or house" because of their sexual identity. Responses to each item were never, once, or twice or more during the past year.

Location. To measure urban-rural distinctions, we asked the question: "What type of community do you currently reside in?" All of the five closeended responses dealt with the population density of that community: rural, small town, midsize city, suburban metropolitan, and center city metropolitan. Participants' responses were recoded into a system of dummy binary variables, with city center metropolitan as the referent group. To help participants identify their community type, our item indicated that metropolitan centers had over 100,000 residents, midsize cities had between 20,000 and 100,000 inhabitants, and small towns had populations under 19,999.

Gender. A response to the question "What is your gender" was coded as male equals 1 and female equals 0 . The nineteen cases with no response for this item were coded as missing data.

Race. Race was treated as a dichotomized variable (white $=1$, while African American, Asian American, Latina/o, and Native American =0). This binary approach was used because some of the racial categories had few respondents. Furthermore, this approach has been useful in previous research on exposure to minority stress as it allows for an analysis of exposure differences based on racial/ethnic minority status (Meyer, Schwartz, and Frost 2008).

Family Income. Income was determined through a scale of family income in the last year (see Barrett and Pollack 2005). In response to a 
question about their "current annual family income," there were five categories that started at under $\$ 20,000$ and ended with above $\$ 151,000$.

Disclosure (Out). Public disclosure of sexual identity was assessed one item from the Public Identification as a Lesbian Scale: "I try not to give any signs that I am gay or lesbian" (Szymanski, Chung, and Balsam 2001). The five-point Lickert scale had strongly disagree coded as 5.

\section{Analytical Plan}

A series of hierarchical OLS regression models tested the relationship between our independent and dependent variables. Model 1 offered an additive analysis of how place of residency and experiences of enacted stigma were connected. Model 2 explored the way in which public disclosures of sexual identities could possibly modify the spatial distribution of heterosexist events (place $\times$ concealment interactions are added to the regression). In doing so, it was assumed that sexual minorities would face higher levels of direct discrimination if they concealed their sexual-minority identities to a lesser degree. Finally, following the added-burden hypothesis, we tested whether membership in disadvantaged social groups influenced exposure to heterosexist experiences in both models. Participants who were missing data on any one variable were excluded from the analysis $(n=17) .^{3}$

\section{Results}

\section{Descriptive Statistics for Enacted Discrimination in the Last Year}

Table 1 offers the descriptive statistics of the enacted stigma items. Cases of recent enacted stigma are relatively rare in this study, but roughly one quarter of the respondents dealt with two or more verbal threats in the last twelve months. Almost ten percent of the sample experienced property damage or were chased because of their sexuality in the same time span, while five percent detected heterosexist employment discrimination.

\section{Place Variables and Recent Enacted Discrimination}

Table 2 displays the results of the regressions for the six types of enacted stigma. We entered place of residency along with disclosure, gender, race, and class factors in the first model and entered area-disclosure interactions in the second model. When exploring the coefficients of determination for model 1 , the $R$-square ranged between .047 and .089 for each form of enacted stigma. The cumulative effects for model 1 were significant for economic discrimination $\left(R^{2}=.089, p<.01\right)$, homophobic statements $\left(R^{2}=.084, p<.01\right)$, and being chased $\left(R^{2}=.062, p<.05\right)$, and the combined predictive capabilities of the variables mostly expanded with the addition of space-disclosure interactions in 
Table 1

Descriptive Statistics for Enacted Discrimination in the Last Year and Independent Variables

\begin{tabular}{|c|c|c|c|}
\hline Enacted discrimination & Never & $\begin{array}{l}\text { Last year } \\
\text { once }\end{array}$ & $\begin{array}{c}\text { Twice or } \\
\text { more }\end{array}$ \\
\hline Denied employment & $247(94 \%)$ & $11(4 \%)$ & $3(1 \%)$ \\
\hline Evicted, denied housing & $258(97 \%)$ & $3(1 \%)$ & $2(1 \%)$ \\
\hline Verbal threats and homophobic statements & $131(49 \%)$ & $56(21 \%)$ & $76(28 \%)$ \\
\hline Personal property damaged & $239(91 \%)$ & $13(5 \%)$ & $9(4 \%)$ \\
\hline Chased or followed & $243(92 \%)$ & $11(4 \%)$ & $7(2 \%)$ \\
\hline Punched, hit, kicked, beaten & $253(97 \%)$ & $6(2 \%)$ & $1(1 \%)$ \\
\hline Categorical independents & & & $\%$ Yes \\
\hline Rural & & & 9 \\
\hline Small town & & & 23 \\
\hline Midsize city & & & 18 \\
\hline Suburb of large urban center & & & 18 \\
\hline Center city of large urban center & & & 26 \\
\hline Missing location & & & 6 \\
\hline Male & & & 58 \\
\hline White & & & 79 \\
\hline Continuous independents & & Mean & $\mathrm{SD}$ \\
\hline Out sexual identity (Scale 5 to 1 ) & & 3.34 & 1.09 \\
\hline Family income (Scale 5 to 1 ) & & 2.82 & 1.08 \\
\hline
\end{tabular}

model 2. This indicates that the regressions that incorporated place-concealment intersections were significant for every enacted discrimination, and model 2 could account for between 8.8 percent and 12.3 percent of the variance in the dependent variables. However, the model containing interaction terms produced lower $R$-square for employment discrimination and being chased.

Spatial Factors. The direction of every coefficient suggested that exposure to heterosexist events increased when people lived in rural and small town areas. However, the associations for location factors were not exceptionally strong when holding the effects of the gender, race, income, and disclosure factors constant. In model 1, rural residencies were significant predictors only of economic employment discrimination $(\beta=.176, p<.01)$ and small town habitancies reached significance for housing discrimination 


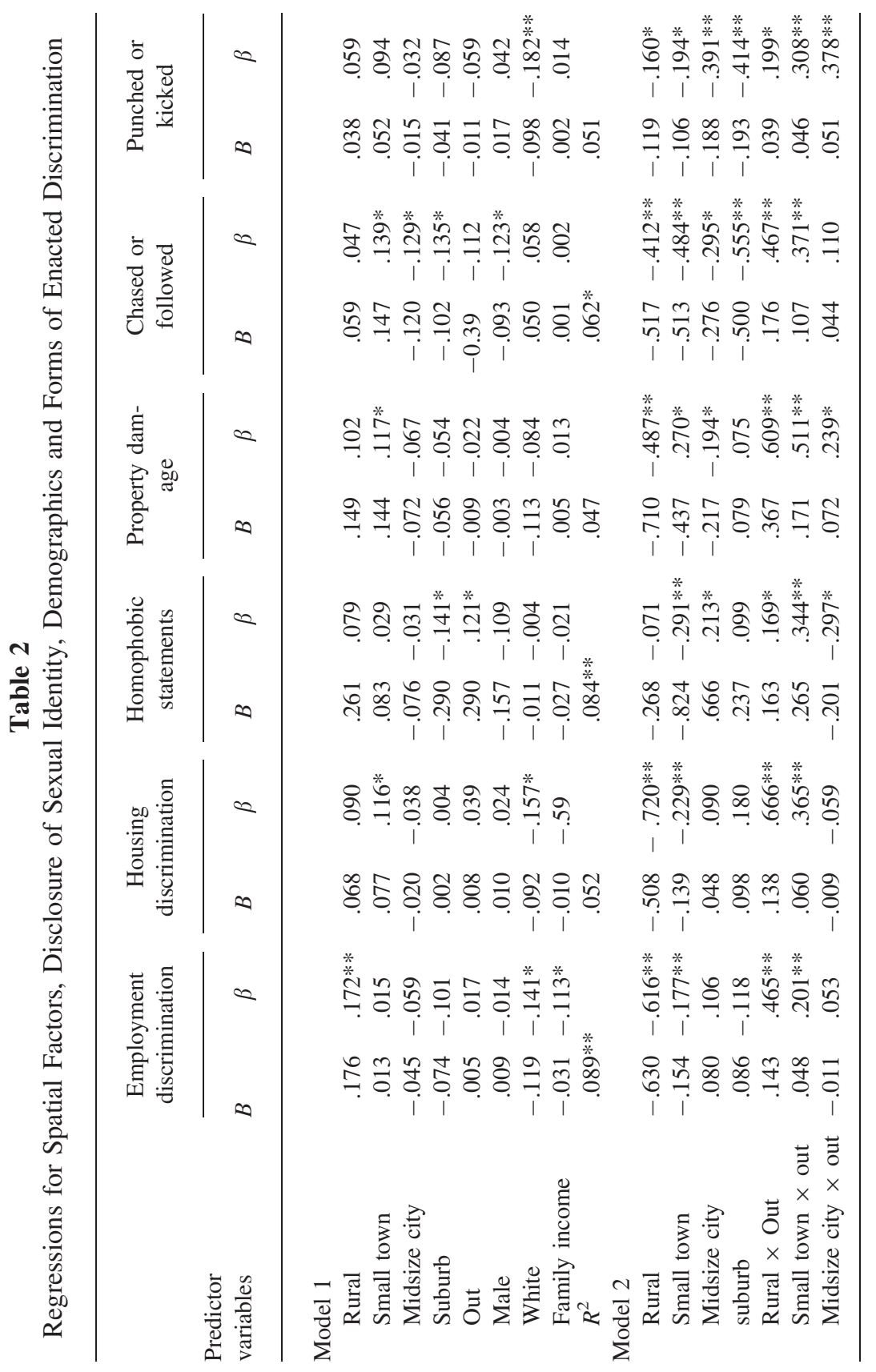




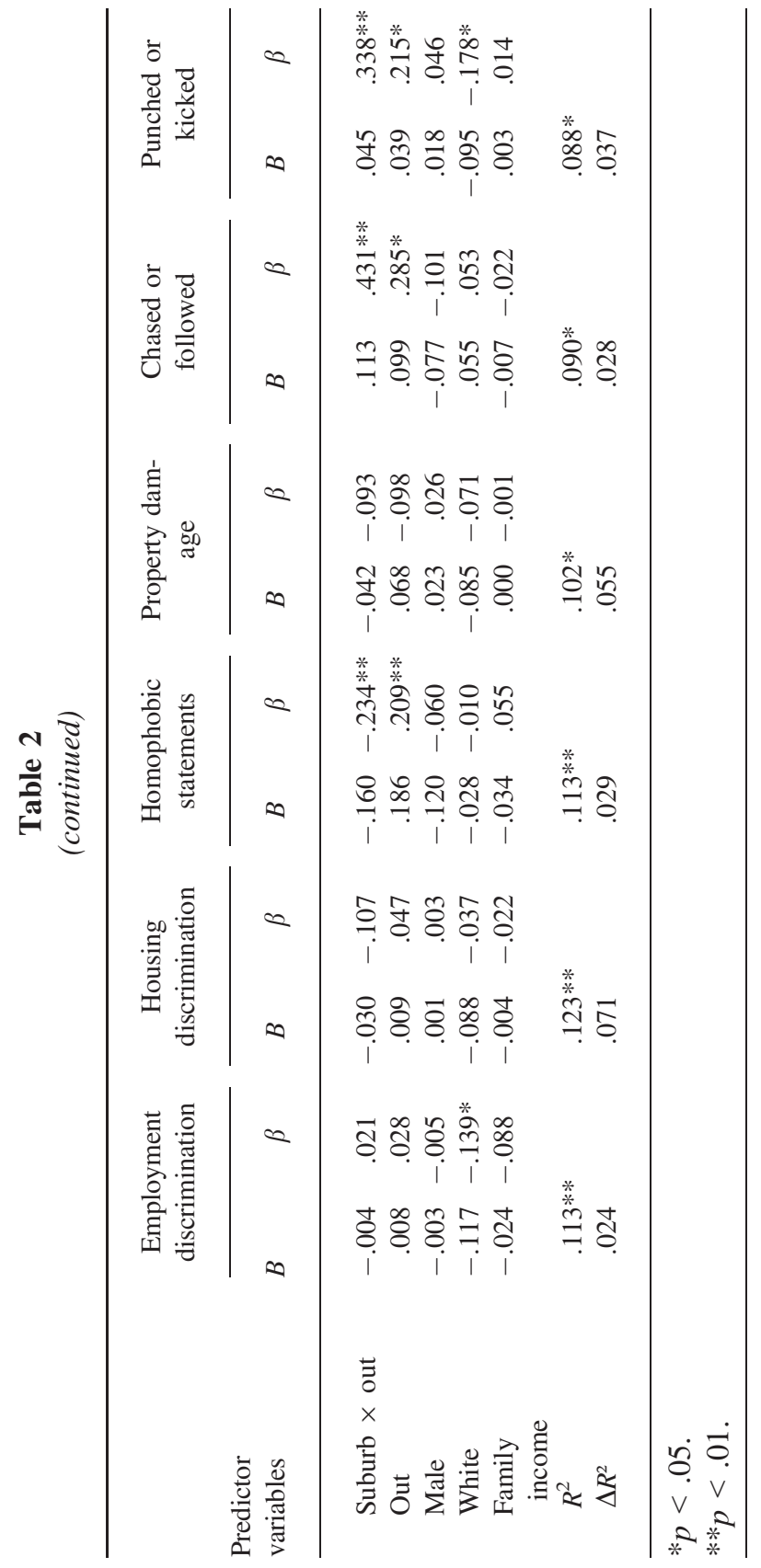



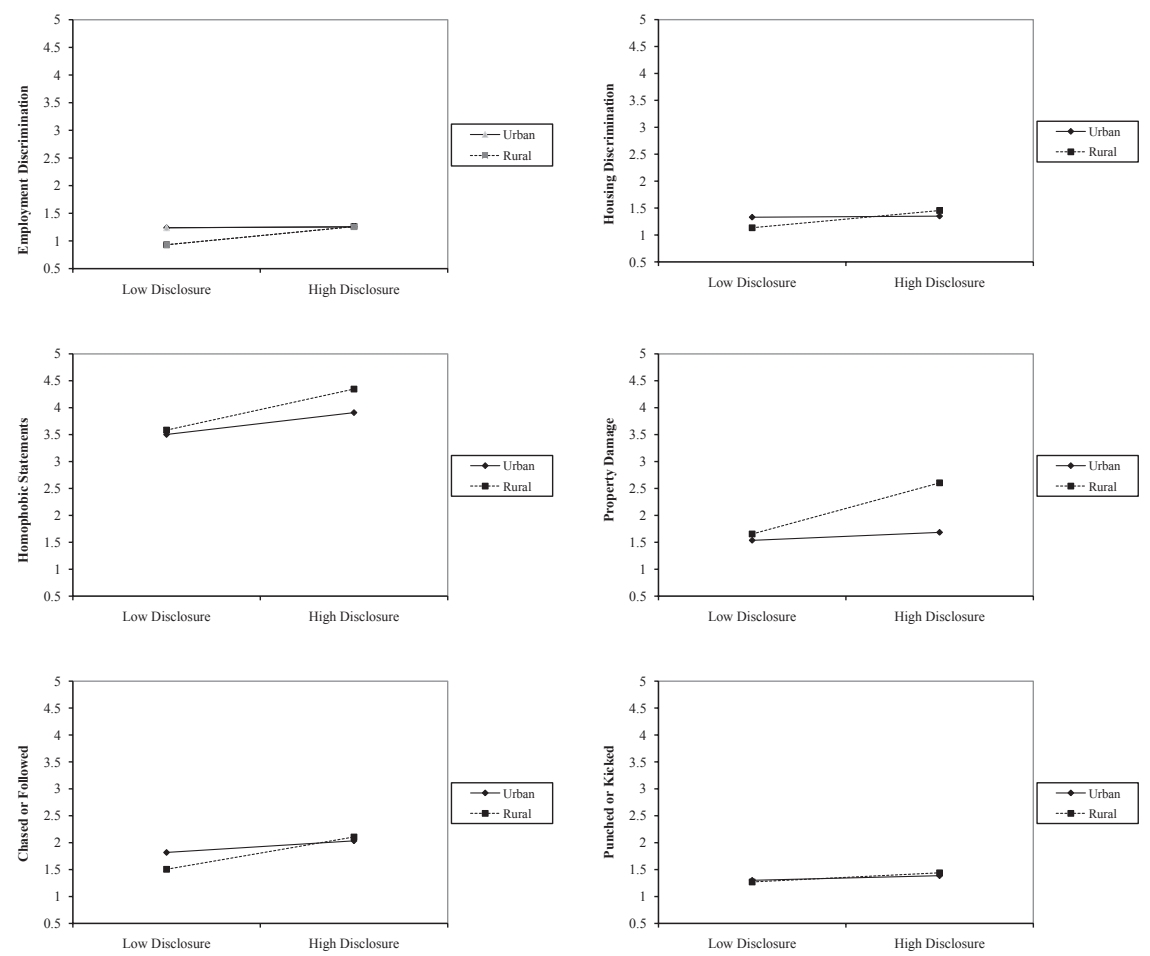

Figure 1 Plots of Interactions Between Disclosure of Sexual Identity and Location in Predicting Forms of Enacted Stigma.

$(\beta=.116, p<.05)$ and property damage $(\beta=.127, p<.05)$. Additionally, living in larger towns and the suburbs mildly suppressed victimization, but suburban factors were significant predictors only of hearing homophobic statements $(\beta=-.138, p<.05)$ and being chased-followed $(\beta=-.135$, $p<.05)$.

Disclosure. As stated earlier, accounting for the interaction between disclosure patterns and spatial factors often augmented the negative effects of rural and small town contexts on exposure to discrimination; that is, more "out" sexual minorities in these settings regularly experienced more discrimination than less "out" sexual minorities in these areas. However, as separate individual variables, disclosure patterns by themselves rarely demonstrated significant associations with the discrimination outcomes. Only in the case of homophobic comments did disclosure by itself demonstrate a significant relationship to an outcome in models 1 and $2(\beta=.121$ and $.200, p<.05,01)$. 
Interactions Between Spatial Factors and Disclosure. The main effects of spatial factors and disclosure reported above must be interpreted in light of the fact that the effects of disclosure on all outcomes were dependent on the location in which sexual minorities lived. As presented in Table 2, model 2, the effects of disclosure on exposure to enacted stigma were magnified in non-urban locations. Figure 1 illustrates this pattern of findings with regard to the differential effects of sexual identity disclosure on enacted stigma across rural and urban locations. Increased disclosure was associated with increased experiences of enacted stigma for sexual minorities living in rural locations. Conversely, increased disclosure had little to no impact on experiences of enacted stigma for urban-living sexual minorities. As further evidenced in Table 2, model 2, similar directional patterns were demonstrated in the statistically significant interactions between disclosure and living in small towns versus urban centers, as being out increased exposure to all types of discrimination for small town residents. While greater disclosures generally increased exposure to discrimination for small towns and rural residents, the location-disclosure phenomena was not as consistent in other areas. Greater disclosure increased the likelihood of experiencing property damage and being punched or kicked in midsized cities; however, there was a slight decrease in hearing homophobic statements for "out" midsized city residents relative to those living in urban centers. Similarly, violent acts were more common among public suburban LGBs, but the direction of the relationship reversed for hearing homophobic statements for suburbanites.

Social Identities. Each of the social statuses demonstrated different associations with enacted stigma outcomes. White sexual minorities routinely reported fewer cases of heterosexist discrimination than people of color. In both models, whites experienced less heterosexist bigotry in employment $(\beta=-.139,-.141, p<.05)$ and avoided violent hate acts more often $(\beta=-182,-.178, p<.01)$ than sexual minorities of color. Whites also dealt with less housing discrimination before the disclosure interactions were entered into the study $(\beta=-.157)$. Larger family incomes also partially protected many sexual minorities from some forms of discrimination. However, higher social-class standing only significantly diminished the chance of being penalized in workplaces (Model 1, $\beta=-.113, p<.05$ ). Finally, gender had less consistent direct effects as findings indicated that lesbians and bisexual women only reported being chased more often than gay and bisexual men (model $1, \beta=.123, p<.05$ ), but this difference diminished when concealment interactions were included in the regression.

\section{Discussion}

This study examined sexual minorities' experiences of heterosexist discrimination as it related to spatial, sexual identity disclosure, race, class, and 
gender factors - $\mathrm{a}$ combination rarely examined in existing quantitative research. This study explored locational and demographic predictors of six types of discriminatory acts. Special attention was given to the geographic dispersion of heterosexist experiences as well as the notion that race, class, and gender differences appeared within sexual minority communities. Finally, this study also explored the ways in which public disclosures of sexual identities can influence exposure to minority stress within and across different types of community locations.

Overall, geographic and locational factors were often related to amounts of reported heterosexist discrimination. Living in rural and small town contexts routinely increased the chances of being victimized, but the relative strength of these residencies varied by discrimination type and individuals' disclosure of their sexual minority status. Before addressing issues of space and identity disclosure interactions, rural residencies were significantly related to employment discrimination, while housing discrimination, property damage, and being chased were significantly connected to small town residencies. After linking location to concealment practices, the impact of small town and rural contexts increased dramatically. "Out" rural and small town sexual minorities confronted all forms of enacted stigma with greater frequency than rural and small-town living sexual minorities who did not disclose their sexual identity. The association between increased disclosure and experiences of enacted stigma was not nearly as pronounced in urban centers or other more urbanized environments such as midsized cities and suburban locations.

These findings provide an interesting window into the role of stigma concealment as a minority stressor. Although concealing one's sexual orientation from others can produce negative mental health outcomes for sexual minorities (Meyer 2003) and can limit the chance of intergroup contact between sexual minorities and heterosexuals (Wood and Bartkowski 2004), concealment may slightly reduce exposure to violent hate crimes and homophobic statements that are more common in rural and small town settings. More research is needed on the interrelations between discrimination and concealment and the degree to which their interrelatedness depends on aspects of social and geographic context.

By exploring the "double jeopardy" hypothesis, this study also examined whether heterosexist discrimination followed traditional gender, race, and social class inequalities. For racial differences, some advantages were conferred to whites regardless of their place of residency. White sexual minorities regularly endured fewer discriminatory practices, with the largest racial impact being found in instances of physical violence and discrimination in housing and labor matters. These patterns replicated elements of Jim Crow racism; discrimination toward people of color has historically been most insidious when dealing with 
the allocation of scarce financial resources and the infliction of hate crime violence (Green, Glaser, and Rich 1998).

Issues of social class were not as paramount in this study, with income only being a significant predictor of employment discrimination. The inverse relationship between salaries and employment biases suggest that heterosexist actions in the workplace were closely related to the authority structure of organizations, as higher echelon employees were treated with more respect. Overall, major differences between gay men and lesbian women were rarely detected when being regressed with covariates, with only the likelihood of being chased being significant for women in the additive model. This suggests that discriminatory events were experienced by gays and lesbians at about similar levels, except in the case of stalking practices. This might be related to the findings that women of any sexual orientation are more likely to be stalked than men (Tjaden and Thoennes 1998). It would be interesting to determine whether exposure to minority stress changed for different regional and race/gender/class interactions, but our cell size was too small to adequately run such regressions for race and class interactions.

This study's findings should be interpreted in light of some limitations. A larger random sample would improve the representativeness of this study and would allow for a wider range of regional or racial diversity in our data. Our discrimination items did not examine every sort of heterosexism, and such omissions could influence the impact of the factors examined in this study. For example, we were unable to explore gender differences for sexual violence because only three respondents reported being raped or sexually assaulted because of their sexual orientation. The measure also failed to identify the sexuality of the perpetrators. Due to patterns of geographic mobility, it is possible that a person's current residency may not always identify the location of discrimination that happened in the past. Consequently, it is possible that a person who lives in a rural area could have experienced discrimination in another geographic area. This study's measures also relied on the participants' judgment about whether an event occurred as a result of prejudice and discrimination. This can be problematic because recognition of discrimination is not restricted to only the occurrence of the event, but also to issues of perception, memory, or even social framing necessary to perceive discrimination. Moreover, the focus on heterosexist events ignores more subtle issues of institutionalized discrimination not related to a specific incident. Research on workplace sexual harassment has shown that negative climates can be detrimental to everyone, not just the target or victim of the attacks (Miner-Rubino and Cortina 2007). Additionally, rural and small towns may lack the groups and organizational resources that improve the quality of life for sexual minorities (i.e., universities, LGBT centers, heterosexual allies, and "gay-friendly" entertainment 
establishments). Our measure of social class would ideally feature data on occupations, work conditions, and assets, but we are limited to family income as an indicator of social class. Finally, our binary measure of gender could minimize gender diversity for some respondents, and there can be temporal ordering problems in the relationship between discrimination and disclosure patterns. It is possible that sexual minorities disclose sexual identities more frequently after they encountered discrimination.

While public disclosures of stigmatized sexual identities often inspired greater amounts of discrimination, these findings should not be seen as suggesting that concealment of sexual minority status is a preferred option for sexual minorities. The minority stress literature suggests that concealment limits access to important personal and interpersonal resources that improve mental health (Diaz et al. 2001; Meyer 2003), and keeping one's sexuality private stunts participation in political movements that strive for LGB rights (Taylor et al. 2009). While concealment may sometimes prevent direct attacks, it also carries detrimental outcomes that deserve critical examination.

Future research should identify the mechanisms that lead to greater overt heterosexism in small towns and rural areas. Initial studies suggest that the link between discrimination and geographic location could be associated with greater concentrations of religious conservatives, homophobic parents, and less educated people in rural areas (Alden and Parker 2005; Barton 2012; McVeigh and Maria-Elena 2009; Moore and Vanneman 2003), less access to economic resources (Green, Glaser, and Rich 1998), or the fact that rural areas have fewer advocacy groups and policies that prohibit sexual orientation discrimination (Grattet, Jenness, and Curry 1998; McVeigh and Maria-Elena 2009; Ragins and Cornwell 2001; Tilcsik 2011). Researchers should also focus on the particular needs of rural LGBs and how they can best receive support in combating heterosexism within their communities. Regardless of the specific topic, research that accurately identifies the factors that allow heterosexism to flourish - often openly and at the expense of LGBs' well-being - must be examined to better advance social justice for people of all sexual identities.

\section{ENDNOTES}

*Please direct Correspondence to Eric Swank, Department of Sociology, Social Work \& Criminology, Morehead State University, 325 Rader Hall, Morehead KY (e.swank@morehead-st. edu).

${ }^{1}$ The terms heteronormativity, heterosexism and homophobia are sometimes used interchangeably when discussing matters of sexual biases. For the rest of this paper we will be using the term homophobia to mean hostile reactions to lesbians and gay men, heterosexism to deal with the 
cultural ideology that justifies discrimination against homosexuals who challenge conventional gender expectations, and heteronormativity as the assumption that sexuality is dichotomous, most people are heterosexual, and that anything other than complete heterosexuality is inferior and unnatural (Herek 2004). Enacted stigma, which is the dependent variable of this study, includes situations in which people, groups, or institutions explicitly dismiss, denigrate, or attack a person because they are not seen as heterosexual.

${ }^{2} \mathrm{We}$ cannot cite statistics from earlier studies because we are not aware of any published data on hate crime or discrimination rates by place of residence. We are hopeful that such studies will become a priority within this literature.

${ }^{3}$ The items for gender and race were skipped the most. Perhaps due to issues of intersexuality or transgender identity, 15 of the participants did not answer this item.

\section{REFERENCES}

Alden, Helema and Karen Parker. 2005. "Gender Role Ideology, Homophobia, and Hate Crimes." Deviant Behavior 26:321-343.

Andersen, Robert and Tina Fetner. 2008. "Economic Inequality and Intolerance: Attitudes toward Homosexuality in 35 Democracies." American Journal of Political Science 52:942-958.

Balsam, Kimberely, Esther Rothblum, and Theodore Beauchaine. 2005. "Victimization over the Lifespan: A comparison of Lesbian, Gay, Bisexual and Heterosexual Siblings." Journal of Consulting and Clinical Psychology 73:477-487.

Balsam, Kimberly, Yamile Molina, Blair Beadnell, Jane Simoni, and Karina Walters. 2011. "Measuring Multiple Minority Stress: LGBT People of Color Microagression Scale." Cultural Diversity and Ethnicity Minority Psychology 17:163-174.

Barrett, Donald and Lance Pollack. 2005. "Whose Gay Community? Social Class, Sexual SelfExpression, and Gay Community Involvement." Sociological Quarterly 46:437-456.

Barton, Bernadette. 2010. "Abomination' Life as a Bible-Belt Gay." Journal of Homosexuality 57:464-484.

- (2012. Pray the Gay Away: The Extraordinary Lives of Bible Belt Gays. New York: NYU Press.

Baunach, Dawn, Elisabeth Burgess, and Courtney Muse. 2010. "Southern (Dis)comfort: Sexual Prejudice and Contact with Gay Men and Lesbians in the South." Sociological Spectrum 30:30-64.

Berrill, Kevin. 1990. "Anti-gay Violence and Victimization in the United States." Journal of Interpersonal Violence 5:274-294.

Blanford, John. 2003. "The Nexus of Sexual Orientation and Gender in the Determination of Earnings." Industrial \& Labor Relation Review 20:622-642.

Bolzendahl, Catherine and Daniel J. Myers. 2004. "Feminist Attitudes and Support for Gender Equality." Social Forces 83:759-790.

Carter, J. Scott and Casey Borch. 2005. "Assessing the Effects of Urbanism and Regionalism on Gender-role Attitudes." Sociological Inquiry 75:548-565.

Chae, David and George Ayala. 2010. "Sexual Orientation and Sexual Behavior among Latino and Asian Americans: Implications for Unfair Treatment and Psychological Distress." Journal of Sex Research 47:451-459.

Collins, Patricia H. 1990. Black Feminist Thought: Knowledge, Consciousness, and the Politics of Empowerment. Boston: Unwin Hyman. 
Connolly, Cathy and Gail Leedy. 2007. "Out in the Cowboy State: A Look at Lesbian and Gay Lives in Wyoming." Journal of Gay \& Lesbian Social Services 19:17-34.

D'Augelli, Anthony and Arnold Grossman. 2001. "Disclosure of Sexual Orientation, Victimization, and Mental Health among Lesbian, Gay, and Bisexual Older Adults." Journal of Interpersonal Violence 16:1008-1027.

Diaz, Rafeal, George Ayala, Edward Bein, Jeff Henne, and Barbara Marin. 2001. "The Impact of Homophobia, Poverty, and Racism on the Mental Health of Gay and Bisexual Latino Men." American Journal of Public Health 91:927-932.

Dunbar, Edward. 2006. "Race, Gender, and Sexual Orientation in Hate Crime Victimization." Violence \& Victims 21:323-337.

Eldridge, Vicki L., Lisa Mack, and Eric Swank. 2006. "Explaining Comfort with Homosexuality in Rural America." Journal of Homosexuality 51:39-56.

Elmslie, Bruce and Edinaldo Tebaldi. 2007. "Sexual Orientation and Labor Market Discrimination." Journal of Labor Research 28:436-453.

Fischer, Claude. 1975. "Toward a Subcultural Theory of Urbanism." American Journal of Sociology 80:1319-1341.

Gonzalez, Adam, Carol Miller, Sondra Solomon, Janice Bunn, and Daniel Cassidy. 2009. "Size Matters: Community Size, HIV status, and Gender Differences." AIDS Behavior 13:12051212.

Grattet, Ryken, Valerie Jenness, and Theodore R. Curry. 1998. "The Homogenization and Differentiation of Hate Crime Law in the United States, 1978 to 1995." American Sociological Review 63:286-307.

Gray, Mary. 2009. Out in the Country: Youth, Media and Queer Visibility in Rural America. New York: New York University Press.

Green, Donald, Jack Glaser, and Andrew Rich. 1998. "From Lynching to Gay Bashing: The Elusive Connection between Economic Conditions and Hate Crime." Journal of Personality and Social Psychology 75:82-92.

Grov, Christian, David Bimbi, José Nanin, and Jeffery Parsons. 2006. "Race, Ethnicity, Gender, and Generational Factors Associated with the Coming-out process among Gays, Lesbians, and Bisexuals." Journal of Sex Research 43:115-121.

Herek, Gregory. 2004. "Beyond "Homophobia": Thinking about Sexual Stigma and Prejudice in the Twenty-First Century." Sexuality Research and Social Policy 1:6-24.

. (2009. "Hate Crimes and Stigma-related Experiences among Sexual Minority Adults in the United States." Journal of Interpersonal Violence 24:54-74.

Huebner, David, Gregory M. Rebchook, and Susan M. Kegeles. 2004. "Experiences of Harassment, Discrimination, and Physical Violence Among Young Gay and Bisexual Men." American Journal of Public Health 94:1200-1203.

Johnson, Nan E. and C. Shannon Stokes. 1984. "Southern Traditionalism and Sex Role Ideology." Sex Roles 10:11-18.

Johnson, Michael, Nick Jackson, Kenneth Arnette, and Steven Koffman. 2005. "Gay and Lesbian Perceptions of Discrimination in Retirement Care Facilities." Journal of Homosexuality 49: $83-102$.

Kane, Melinda. 2007. "Timing Matters: Shifts in the Causal Determinants of Sodomy Law Decriminalization, 1961-1998." Social Problems 54:211-239.

Kazyak, Emily. 2011. "Disrupting Cultural Selves: Constructing Gay and Lesbian Identities in Rural Locales." Qualitative Sociology 34:561-581.

Kosciw, Joseph, Emily Greytak, and Elizabeth Diaz. 2009. "Who, What, Where, When, and Why: Demographics and Ecological Factors Contributing to Hostile School Climates for Lesbian, Gay, Bisexual and Transgender Youth.” Journal of Youth and Adolescence 30:976-988. 
Lauster, Nathanael and Adam Easterbrook. 2011. "No Room for New Families? A Field Experiment Measuring Parental Discrimination against Same-Sex Couples and Single Parents." Social Problems 58:389-409.

Lewis, Gregory. 2003. "Black-White Differences in Attitudes toward Homosexuality and Gay Rights." The Public Opinion Quarterly 67:59-78.

Loftus, Jeni. 2001. "America's Liberalization in Attitudes toward Homosexuals." American Sociological Review 66:762-782.

Lombardi, Emilia, Riki Wilchins, Dana Priesing, and Diana Malouf. 2001. "Gender Violence: Transgender Experiences with Violence and Discrimination." Journal of Homosexuality 42: 89-101.

McCarthy, Linda. 2000. "Poppies in a Wheat Field: Exploring the Lives of Rural Lesbians." Journal of Homosexuality 39:75-90.

McVeigh, Rory and D. Diaz Maria-Elena. 2009. "Voting to Ban Same-Sex Marriage: Interests, Values, and Communities." American Sociological Review 74:891-915.

Meyer, Ilan. 2003. "Prejudice, Social Stress, and Mental Health in Lesbian, Gay, and Bisexual Populations." Psychological Bulletin 129:674-697.

Meyer, Ilan, Sharon Schwartz, and David Frost. 2008. "Social Patterning of Stress and Coping: Does Disadvantaged Social Status Confer More Stress and Fewer Coping Resources?" Social Science \& Medicine 67:368-379.

Mezey, Nancy. 2008. "The Privilege of Coming Out: Race, Class, and Lesbians' Mothering Decisions." International Journal of Sociology of the Family 34:257-276.

Miller, Michael and Albert E. Luloff. 1981. "Who is Rural?" Rural Sociology 46:608-625.

Miner-Rubino, Kathi and Lilia Cortina. 2007. "Beyond Targets: Consequences of Vicarious Exposure to Misogyny at Work.” Journal of Applied Psychology 92:1254-1269.

Moore, Laura and Reeve Vanneman. 2003. "Context Matters: Effects of the Proportion of Fundamentalists on Gender Attitudes." Social Forces 82:115-139.

Pilkington, Neil and Anthony D'Augelli. 1995. "Victimization of Lesbian, Gay, and Bisexual Youth in Community Settings." Journal of Community Psychology 23:34-56.

Poon, Colleen and Elizabeth Saewyc. 2009. "Out Yonder: Sexual-Minority Adolescents in Rural Communities in British Columbia." American Journal of Public Health 99:118-124.

Puckett, Julia, Sharon Horne, Heidi Levitt, and Teresa Reeves. 2011. "Out in the Country: Rural Sexual Minority Mothers." Journal of Lesbian Studies 15:176-186.

Ragins, Belle and John Cornwell. 2001. "Pink Triangles: Antecedents and Consequences of Perceived Workplace Discrimination against Gay and Lesbian Employees." Journal of Applied Psychology 86:1244-1261.

Rice, Tom and Diane Coates. 1995. "Gender Role Attitudes in the Southern United States." Gender \& Society 9:774-756.

Rosenfeld, Michael and Byung-Soo Kim. 2006. "The Independence of Young Adults and the Rise of Interracial and Same-Sex Unions." American Sociological Review 70:541-562.

Rostosky, Sharon, Ellen Riggle, Sharon Horne, and Angela Miller. 2009. "Marriage Amendments and Psychological Distress in Lesbian, Gay, and Bisexual Adults." Journal of Counseling Psychology 56:56-66.

Schulte, Lisa and Juan Battle. 2004. "The Relative Importance of Ethnicity and Religion in Predicting Attitudes towards Gays and Lesbians." Journal of Homosexuality 47:127-142.

Soule, Sarah. 2004. "Going to the Chapel? Same-Sex Marriage Bans in the United States, 19732000." Social Problems 51:453-477.

Szymanski, Dawn, Barry Chung, and Kimberly Balsam. 2001. "Psychological Correlates of Internalized Homophobia in Lesbians." Measurement and Evaluation in Counseling and Development 34:27-41. 
Szymanski, Dawn and Mi R. Sung. 2010. "Minority Stress and Psychological Distress among Asian American Sexual Minority Persons." The Counseling Psychologist 38:848-872.

Taylor, Verta and Nicole Raeburn. 1995. "Identity Politics as High-Risk Activism: Career Consequences for Lesbian, Gay, and Bisexual Sociologists." Social Problems 42:252-273.

Taylor, Verta, Kim Kimport, Nella Van Dyke, and Ellen Andersen. 2009. "Culture and Mobilization: Tactical Repertoires, Same-sex Weddings, and the Impact on Gay Activism." American Sociological Review 74:865-890.

Tewksbury, Richard, Elizabeth Grossi, Geetha Suresh, and Jeff Helms. 1999. "Hate Crimes against Gay Men and Lesbian Women." Humanity and Society 23:125-142.

Tilcsik, András. 2011. "Pride and Prejudice: Employment Discrimination against Openly Gay Men in the United States." American Journal of Sociology 117:586-626.

Tjaden, Patricia and Nancy Thoennes. 1998. Stalking in America: Findings from the National Violence Against Women Survey. Washington, DC: U.S. Department of Justice.

Van Dyke, Nella, Sarah Soule, and Rebecca Windom. 2001. "The Politics of Hate: Explaining Variation in the Incidence of Anti-gay Hate Crime." Research in Political Sociology 9:35-58.

Waldo, Craig, Matthew Hesson-McInnnis, and Anthony D'Augelli. 1998. "Antecedents and Consequences of Victimization of Lesbian, Gay, and Bisexual Young People." American Journal of Community Psychology 26:307-333.

Ward, James and Diana Winstanley. 2006. "Coming Out at Work." The Sociological Review 53:447-475.

Weston, Kath. 1995. "Get Thee to a Big City: Sexual Imaginary and the Great Gay Migration." GLQ: A Journal of Lesbian and Gay Studies 2:253-277.

Wirth, Lois. 1938. "Urbanism as a Way of Life." American Journal of Sociology 44:1-24.

Wood, Peter B. and John P. Bartkowski. 2004. "Attribution Style and Public Policy Attitudes toward Gay Rights." Social Science Quarterly 85:58-74. 